
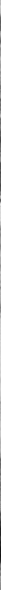

\title{
Arte público, ciencia y patrimonio en el entorno rural: el caso de Murales Conciencia
}

\author{
Diego Ortega-Alonso, Juan Jesús Padilla Fernández
}

\begin{abstract}
Resumen: En un universo global donde el mundo rural tan solo se concibe como un entorno secundario, destinado preferentemente a la generación de recursos económicos y vacacionales, el arte se convierte en una herramienta válida para generar nuevos estímulos que permitan su recuperación como espacio de vida. Concretamente, el proyecto Murales Conciencia, desarrollado en Bailén (Jaén), plantea la creación de una colección de arte público a través de la utilización del propio municipio como continente, que se completa con un museo virtual. Artistas relevantes en el ámbito de la tipología mural, han conformado una colección única que se fundamenta en dos pilares básicos: el Patrimonio y la Ciencia. En este trabajo abordamos la construcción de un proyecto singular que, además de reconvertir estéticamente enclaves denostados de la localidad, ha favorecido la creación de ámbitos comunitarios y de memoria, repletos de conocimiento y responsabilidad social.
\end{abstract}

Palabras clave: arte público, museo virtual, innovación social, comunicación científica, pintura mural, patrimonio

\section{Public art, science and heritage in the rural environment: the case of Murales Conciencia}

Abstract: In a universe where the rural world is only conceived of as a secondary environment, preferably exploited for the generation of economic and holiday resources, art becomes a valid tool to generate new stimuli that allow its recovery as an authentic living space. Specifically, the Murales Conciencia project, developed in Bailén (Jaén, Spain), proposes the creation of a public art collection by using the municipality itself as a continent, which is completed with a virtual museum. Relevant artists in the field of mural typology have formed a unique collection that is based on two basic pillars: Heritage and Science. In this work, we describe a unique project that, in addition to aesthetically converting sites in the town endangered by gentrification, has favored the creation of community and memory areas, full of knowledge and social responsibility.

Key words: public art, virtual museum, social innovation, scientific communication, mural painting, heritage

\section{Museos del Siglo XXI}

¿A qué llamamos museo? Dar respuesta a esta pregunta está suscitando en la actualidad una gran discusión dentro del ICOM, la mayor organización internacional de museos y profesionales ligada a la Unesco. Para una parte de este Consejo Internacional, la definición acordada en 2007 (un calco de la de 2001 y ésta, a su vez, de la de 1995, 1989 y 1974) todavía se considera como la más adecuada (Hernández 1993). Para ellos, los museos siguen siendo instituciones permanentes y sin ánimo de lucro al servicio de la sociedad y su desarrollo, abiertas al público, que adquieren, conservan, investigan, comunican y exhiben el patrimonio tangible e intangible de la humanidad y su entorno con fines de educación, estudio y disfrute.

El nuevo significado que pretende implantarse es muy distinto de los que han sido aceptados hasta ahora (ICOM 2019) [1]. De hecho, presenta cambios estructurales importantes al entenderse que la definición que actualmente permanece en vigor, no atiende a la complejidad inherente de los museos, ni deja claros sus compromisos, responsabilidades, desafíos y visiones para el futuro. En este sentido, el comité permanente 
que se encarga de plantear las nuevas perspectivas y potencialidades de un museo, lo concibe como un lugar democratizado, inclusivo y polifónico para el diálogo, crítico sobre el pasado y el futuro, que reconoce y aborda los conflictos y desafíos del presente, mantiene los artefactos y objetos que le han sido confiados por la sociedad, salvaguarda la diversidad de la memoria para las generaciones futuras, y garantiza la igualdad de derechos y el acceso al patrimonio para todas las personas. Asimismo, los museos no deben tener ánimo de lucro y se les exige ser participativos, transparentes y trabajadores activos en la recopilación, preservación, investigación, interpretación y exhibición del mundo, y deben tener como principal objetivo contribuir a la dignidad humana y la justicia social, la igualdad global y el bienestar planetario. De acuerdo con esto, a partir de ahora se decide apostar por conceptos como la inclusión, para dar visibilidad a la diversidad de la sociedad y poder atender las necesidades de todos los públicos. Otras nociones importantes son la de transparencia, dignidad, justicia, igualdad y bienestar, apuntalando el papel crucial que los profesionales de los museos tienen en la sociedad a la que se dirigen. Sin duda, se trata de toda una declaración de intenciones que pretende transformar por completo la concepción tradicional de dicho término y comprometerse con las necesidades e intereses del nuevo público, al menos en los próximos años, hasta que la propia evolución de la humanidad en su conjunto demande nuevos planteamientos y necesidades.

Ante tal coyuntura, el proyecto Murales Conciencia, desarrollado desde el Ayuntamiento de Bailén gracias a la concesión de una ayuda para el Fomento de la Cultura Científica, Tecnológica y de la Innovación por parte de la Fundación Española para la Ciencia y la Tecnología (FECYT), ha permitido materializar un museo en abierto, entendido este como un espacio público patrimonial, democrático e inclusivo que cuenta con los artefactos artísticos necesarios para establecer una interacción recíproca con la ciudadanía, tanto de forma física como a través de recursos tecnológicos y plataformas digitales. El proyecto muestra la necesidad de traspasar las fronteras establecidas y entender los museos como entes diáfanos y componentes fundamentales en los procesos de "hacer ciudad", mediante la generación de artefactos de carácter artístico (Remesar 2019: 9) que propicien una interrelación entre el patrimonio local y la comunicación social de la ciencia, y que potencian el cuidado, mantenimiento y mejora de los ámbitos de vida compartidos por la comunidad.

\section{Ciencia, arte público, patrimonio y turismo en un contexto rural}

Bailén, localidad de la provincia de Jaén con una población de 17.820 habitantes (según los datos registrados en el Instituto Nacional de Estadística, en su censo de 2018), Ilegó a ser el primer productor de España de cerámica estructural, alcanzando alrededor de un 30\% de la producción nacional (Cárdenas y Agudo 2012). La denominada crisis del ladrillo supuso para este municipio un varapalo socioeconómico que le llevó a superar el 35\% de desempleo y a perder un millar de habitantes en una década (2). En este contexto de emergencia social y económica, Bailén fue contando con multitud de infraestructuras urbanas degradadas o abandonadas, que invitaban a plantear acciones para su mejora o mantenimiento. El aprovechamiento de estos espacios para la generación de nuevos artefactos culturales con utilidades inmediatas y cercanas (Martos y García 2014: 123), podría ser utilizado para recuperar una estética identitaria, que confiriese a los habitantes del municipio un sentimiento de pertenencia a través del establecimiento de un nuevo vínculo social. Además, constituirse en otro recurso turístico que, en línea con proyectos similares instaurados en el territorio, generase un impacto socioeconómico real en la vida del municipio. En este sentido, el arte es una herramienta eficaz para la aplicación de diversos procesos como la cohesión del grupo, la transformación y la participación ciudadana, ya que incide directamente en el desarrollo comunitario y social y en el bienestar de los sujetos (Serrano-Martínez 2016: 25), pese a la inicial "necesidad de desarrollar procesos de regeneración más centrados en las personas y no tanto en el entorno físico" (Remesar, 2019: 28) [figura 1].

El proyecto Murales Conciencia se puede enmarcar en el ámbito de la definición que Remesar realizó sobre el arte público (2010) cuando se refiere al "conjunto de las intervenciones estéticas que, interviniendo sobre el territorio, desencadenan mecanismos sociales e individuales de apropiación del espacio que contribuyen a co-producir el sentido del lugar". Los elementos patrimoniales con los que contaba la localidad, como monumentos, edificios históricos o el Museo de la Batalla de Bailén, se ven complementados por otros nuevos que no solo generan una dinamización cultural alternativa en

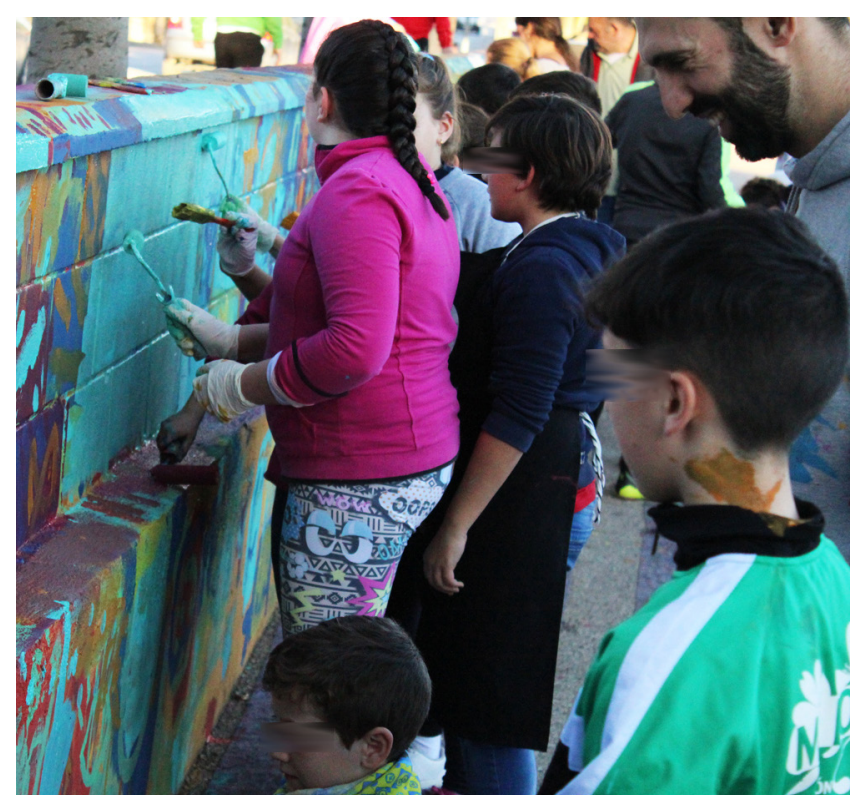

Figura 1.- Proceso de creación de la acción Simbiosis, a cargo de Boa Mistura, con la participación de más de 600 personas. 
el municipio, sino que además se constituyen como un nuevo recurso que se puede abordar desde la perspectiva del turismo cultural, en la misma línea de otros proyectos llevados a cabo con éxito, como, las rutas del Niño de las Pinturas en Granada, Madrid Street Art Project en Madrid, las de Belin en Linares (Jaén), o Festivales como ASALTO en Zaragoza, MIAU Fanzara (Castellón) o MAUS en Málaga, por citar solo algunos ejemplos (García y García 2016: 133; Ortega-Alonso 2018: 190).

Silberberg (1995) se refirió al turismo cultural como "las visitas realizadas por personas de fuera de la comunidad receptora, que están motivadas total o parcialmente, por el interés histórico, artístico, científico, además de las costumbres y modos de vida que puede brindar una comunidad, región, grupooinstitución".Más recientemente, en la Conferencia de la Organización Mundial del Turismo (OMT) y la Unesco, celebrada en Turquía en diciembre de 2018, una de las conclusiones alcanzadas se refiere a las políticas y estrategias de turismo cultural, indicándose que "deben considerar las perspectivas e intereses de las comunidades locales, que también pueden ayudar a los organismos de gobernanza a hallar un equilibrio entre el desarrollo del turismo y la conservación y salvaguarda del patrimonio." Ambas perspectivas inciden en la necesidad de involucrar a la comunidad en lo que le es propio.

En una sociedad de consumo como la actual, en la que los productos artísticos que llegan al ciudadano medio en general, y rural en particular, están muy influenciados tanto geográficamente (por su carácter descentralizado) como económicamente - por la enorme influencia de los mass media en la construcción de una cultura de consumo, la mayoría de las veces "de usar y tirar"—, se torna necesario que los organismos públicos e instituciones los contrarresten, preservando y fomentando el patrimonio y la cultura, mediante el desarrollo de estrategias y acciones que garanticen una alternativa viable y de suficiente calidad para garantizar su perdurabilidad. Como afirma Bauman (2010), con la aparición de estos mercados de consumo, los agentes y administradores deben ocupar un papel neutral sobre el consumo de la cultura y el comportamiento humano "normativamente regulado" hacia los administrados (sociedad), asignándole a la educación un papel fundamental. Así pues, el espacio público debe entenderse como un bien colectivo, donde el sentido de pertenencia de la comunidad y el diálogo con el mismo lo instaura como lugar significativo, con capacidad para estimular los intercambios dialécticos y dialógicos entre todas las partes implicadas (Visconti, Sherry, Borghini y Anderson 2010: 511).

Murales Conciencia ha resultado ser un revulsivo que no solo ha conseguido acercar la ciencia a toda clase de públicos, sino que además, ha aportado valor estético, cultural, patrimonial y turístico a la localidad. Así pues, el proyecto surge con la intención de crear espacios agradables y prósperos para sus habitantes y visitantes, documentando los procesos de creación de los murales y la interacción entre artistas y ciudadanía. En connivencia con los propietarios de los edificios objeto de las intervenciones pictóricas, se han plasmado en murales diversas temáticas relacionadas directa o indirectamente con la ciencia (Ortega-Alonso 2018: 189) [figura 2]

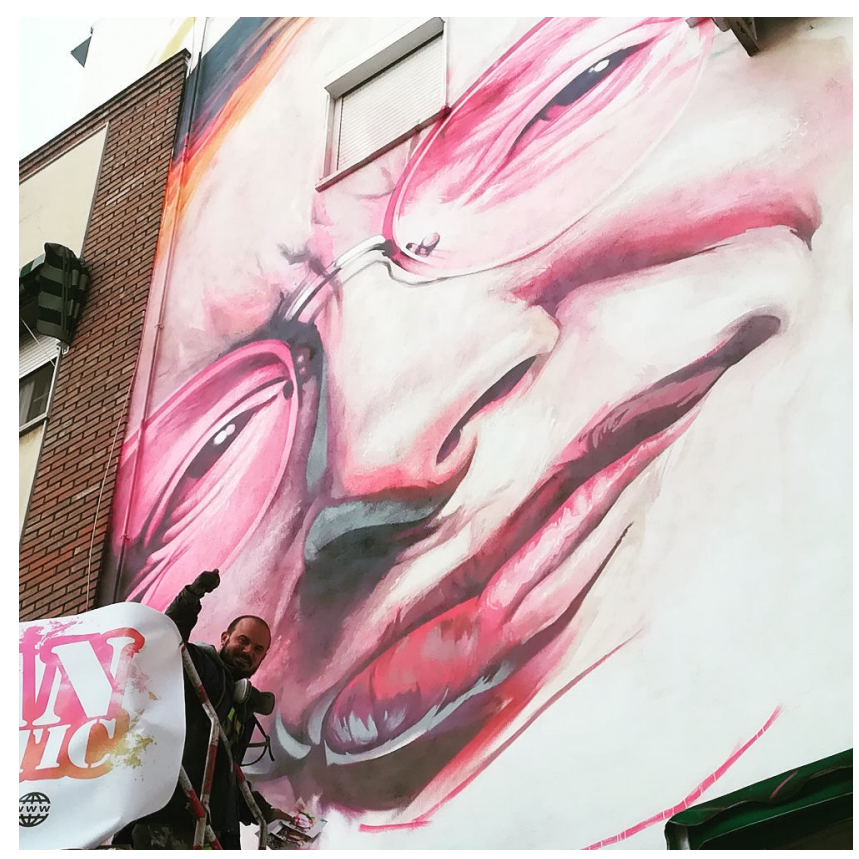

Figura 2.- Adrián Pérez "Manomatic" ejecutando Hawking y la universalidad del AOVE.

El carácter público de la pintura mural en el contexto urbano de una sociedad como la actual, tan expuesta a tecnologías que nos interconectan —la mayoría de índole audiovisual e interactiva-, permite difundir cualquier tipo de expresión artística a todos los confines del mundo, con independencia de (o incluso gracias a) su localización, y proyecta culturalmente estas intervenciones como lugares que visitar. El proyecto Murales Conciencia ha conseguido transformar estéticamente la localidad de Bailén (Jaén), dotándola de un nuevo recurso inexistente hasta el momento. La unión de elementos de carácter artístico (pintura mural), con una sólida apuesta por la comunicación social de la ciencia, ha convertido la localidad en un ecosistema museístico de divulgación innovadora, utilizando elementos tecnológicos de geolocalización, promoción y difusión por la red de Internet.

Nos encontramos ante un proyecto de innovación social que promueve la interacción entre diversas formas de conocimiento, y la resolución colectiva e inclusiva de problemas que incluyen a sus protagonistas a través de metodologías participativas, generando bienes colectivos y comunes, así como una movilización distinta de los actores de la sociedad (Lora y Rocha 2016: 176). Pero ¿por qué ciencia? Es ésta una pregunta que frecuentemente se ha planteado durante los procesos de ejecución de las diferentes intervenciones artísticas. En este punto, cabe recordar los objetivos específicos del proyecto 
Murales Conciencia, recogidos en la memoria técnica de la Convocatoria 2017 de ayudas para el Fomento de la Cultura Científica, Tecnológica y de la Innovación, los cuales son:

-Aportar conocimiento sobre aspectos científicos concretos que son comunes, y que son vistos como muy abstractos y alejados de la sociedad.

-Impulsar la localidad de Bailén a través de la realización de recorridos artísticos con la ciencia como protagonista, por medios electrónicos e impresos, configurando un nuevo atractivo turístico al municipio.

-Creación de actividades paralelas al certamen, que impulsen sectores locales como la hostelería o el comercio (conferencias, talleres, simposios...)

-Establecer vínculos y sinergias con municipios y ciudades que ya cuentan con recorridos y oferta turística específica en torno al arte público, así como con otras entidades relacionadas con el mundo de la divulgación científica.

-Promover y difundir el evento a través de la plataforma Exploria Ciencia, tras convenio firmado con la Fundación Descubre. En esta plataforma aparecerán los siguientes aspectos:

-Presentación de los artistas y de los proyectos de divulgación científica que trabajarán.

-Procesos de creación de las obras.

-Información de carácter científico con las temáticas abordadas.

-Promoción y difusión a través de redes sociales e internet.

Desde el año 2002, la FECYT recoge bianualmente el análisis y los resultados de la Encuesta de Percepción Social de la Ciencia y la Tecnología en España, cuyo fin es "profundizar en el conocimiento de las relaciones entre ciencia, tecnología y sociedad y analizar la percepción de la ciudadanía sobre los avances científicos y tecnológicos, y sobre la capacidad de éstos para la mejora de la calidad de vida de la población". Los datos que arroja la última encuesta (2018) indican que el interés suscitado por los temas científicos y tecnológicos de la sociedad española se sitúa en torno al $16,3 \%$, en una tendencia ascendente que, sin embargo, parece haberse estancado en los últimos años. En cuanto a la alfabetización científica general, se considera que el nivel de educación científico-técnico es bajo, o al menos más bajo de lo que se desearía, ya que el $40,6 \%$ de las personas encuestadas lo califica así, frente al $12,6 \%$ que lo considera muy alto $(1,6 \%)$ o alto $(10,9 \%)$. La búsqueda del incremento del interés de la ciudadanía en ámbitos científico-técnicos responde a una de las razones que justifican esta necesidad. En palabras de Toharia
(2010): "Cuando se difunde ese tipo de cultura científica, cuando se educa a toda la población de manera informal y atendiendo más a sus curiosidades e inquietudes que a una mera formación erudita y sistemática, se está contribuyendo a incrementar el nivel medio de la educación científica global, hoy por hoy bajo mínimos."

Otra de las razones se encuentra en la reivindicación de la innovación disruptiva (Christensen, Raynor y Mcdonald 2015: 4) que supone incluir algo tan, a priori, ajeno a la cotidianidad de lo rural como puede ser el conocimiento científico. A través de expresiones artísticas que generan nuevos recursos visuales, y vinculan lo que es propio de la identidad colectiva de un pueblo con cuestiones de relevancia para la sociedad, se consiguen crear nuevas identidades que encuentran de este modo los canales adecuados para su comunicación social [figura 3].

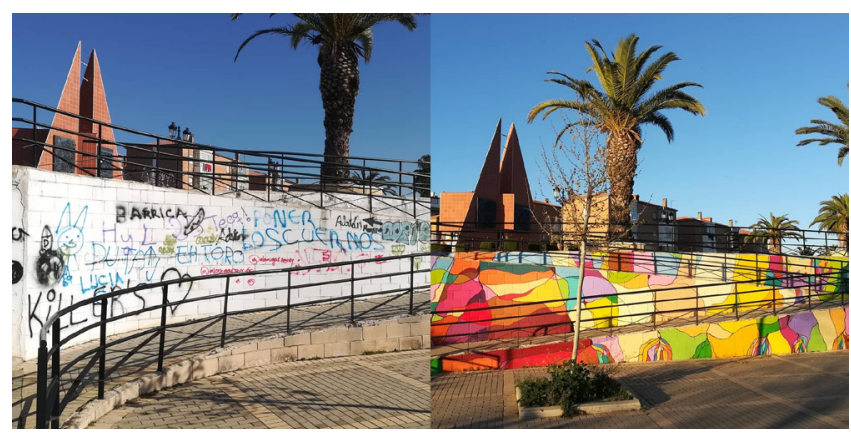

Figura 3.- Vista del antes y el después de la intervención Bosque de neuronas de Ramón Pérez Sendra.

Si bien la previsión inicial del proyecto era la de realizar quince murales, la idiosincrasia de los espacios y el presupuesto disponible supusieron la reducción de este número hasta un total de nueve, tal y como puede verse en el recorrido museístico virtual (3). Como contrapartida, los artistas han podido abordar obras de un tamaño muy superior al inicialmente previsto, con el consiguiente impacto que causa su monumentalidad, al estar ubicadas en espacios públicos como paredes medianeras, accesos a plazas o muros que, en algunos casos, llevaban más de medio siglo sin haber sido siquiera pintados con pintura de exteriores.

\section{Los Murales Conciencia}

Comoya se ha mencionado, uno de los factores diferenciales de Murales Conciencia, más allá de ser una colección de arte público, reside en su musealización virtual, que permite la interacción del público con las obras artísticas, el registro audiovisual de los procesos de creación de las mismas [4] y una apuesta por la comunicación social de la ciencia a través de descripciones textuales y audiodescritas, así como enlaces a contenidos en la red de internet. Esta tarea, por tanto, se materializa desde el espectro físico pero también a través del uso de herramientas digitales. 
Dicho museo virtual está incluido dentro de la plataforma Exploria Ciencia, de la Fundación Descubre, una institución privada y sin ánimo de lucro impulsada por la Consejería de Conocimiento, Investigación y Universidad de la Junta de Andalucía, cuyo compromiso institucional reside en comunicar ciencia a la sociedad. La plataforma permite, de forma sencilla e intuitiva, navegar por una panorámica en $360^{\circ}$ de cada uno de los murales, conocer más sobre quién los hizo, cómo, cuándo, por qué y para qué. La distribución, en los puntos de interés turístico y cultural de la localidad, de dípticos impresos informativos sobre la ubicación geográfica de los murales y su vinculación a la plataforma digital a través del uso de códigos QR, permiten la interacción entre la ruta urbana y el museo virtual [figura $4]$.
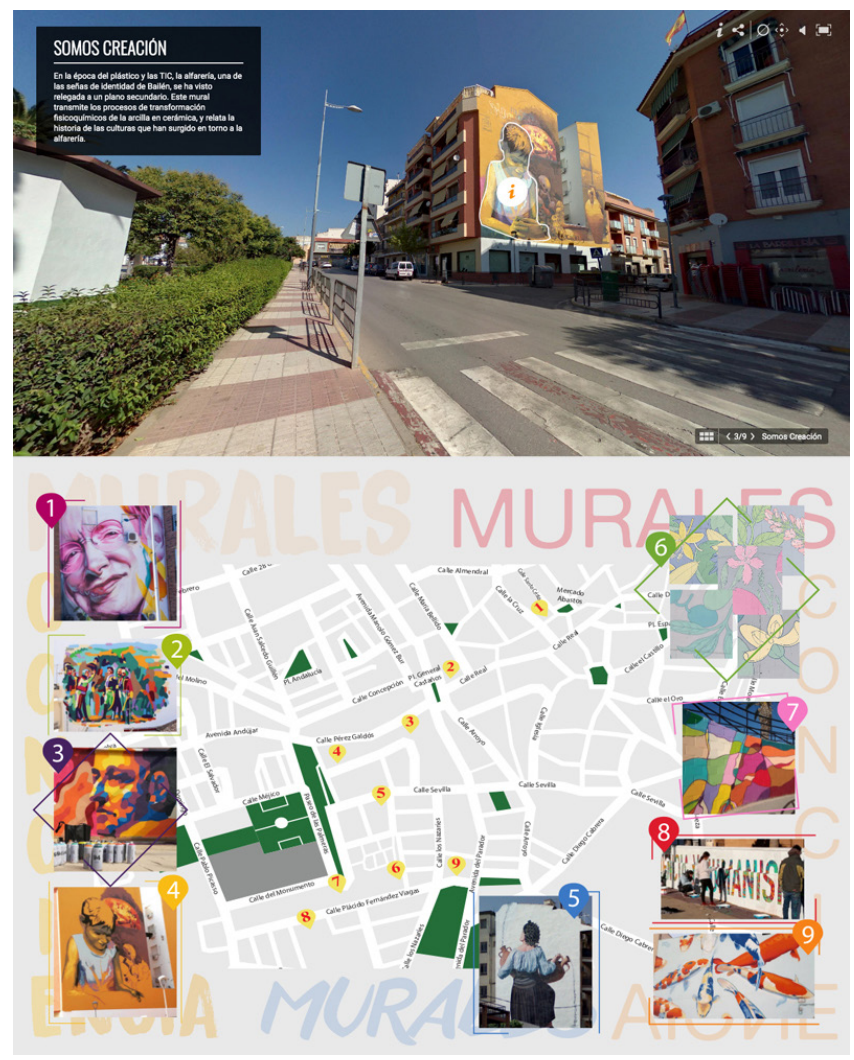

Figura 4.- Vista del museo virtual Murales Conciencia en plataforma Explora Ciencia. Fundación Descubre. (Abajo): Plano con la ubicación de los murales para su recorrido en Bailén. Ilustración de los autores.

Este artículo no estaría completo sin describir cada una de las temáticas científicas de las obras que componen los Murales Conciencia. Los artistas partían de una propuesta inicial formulada por los responsables del proyecto, y condicionada por aspectos como el conocimiento de los espacios y lugares del municipio, el contexto de las intervenciones o el interés por temáticas concretas que dotaran al itinerario de mayor riqueza patrimonial y científica. En este sentido, los artistas desarrollaron una investigación propia de procesos, en ocasiones, cercanos a los de la ilustración científica, mediante documentación basada en bibliografía o a través de la investigación directa, de carácter tanto metodológico como epistemológico y gnoseológico. Sin coartar en ningún caso a los autores en su libertad creadora o su lenguaje expresivo, éstos acumularon grandes conocimientos que propiciaron resultados artísticos personales y fundamentados en el ámbito del encargo (Ortega-Alonso 2019: 61).

\section{La Rendición de Bailén}

La vida bailenense gira en torno a la plaza General Castaños, como espacio público y de encuentro. Además, como su propio nombre indica, se trata de una plaza ligada a la Batalla de Bailén, hecho histórico que ha dado al municipio una fama internacional y que la ha situado en los libros de Historia. Debido precisamente a su singularidad,el proyecto Murales Conciencia inició su andadura en este lugar, uno de los puntos neurálgicos de la ciudad. Esta intervención de Ramón Pérez Sendra es una reinterpretación de la obra del pintor romántico Casado del Alisal, que plasmó en un lienzo la primera derrota de Napoleón en campo abierto, tomando como referencia La Rendición de Breda de Velázquez. El mural hace referencia a este hecho, pero además, a la teoría y la percepción del color: en la retina del ojo existen millones de células especializadas en detectar las longitudes de onda procedentes de nuestro entorno. Estas células fotorreceptoras, los conos y los bastones, recogen parte del espectro de la luz y, gracias al efecto fotoeléctrico, lo transforman en impulsos eléctricos, que son enviados al cerebro a través de los nervios ópticos, para crear la sensación del color.

\section{Los peces del Vivero}

La memoria social también es patrimonio. Durante más de tres generaciones, el estanque emplazado en el jardín del Parque D. Eduardo Carvajal (conocido popularmente como El Vivero) contó con una estimable población de carpas japonesas Cyprinus carpio koi, y fue protagonista del esparcimiento familiar bailenense. Antes de la llegada de la revolución tecnológica, este espacio era uno de los más frecuentados por las familias en días no lectivos, porque en él los niños podían jugar y pasear sin peligro, así como observar y dar de comer a estos peces de gran tamaño y colores llamativos. Por tanto, el valor patrimonial de este mural es inmaterial, y reside en el recuerdo de los habitantes de Bailén, pero la obra también aprovecha para tratar un tema de especial relevancia en la actualidad y que es uno de los principales causantes de pérdida de biodiversidad: las especies exóticas invasoras y su incidencia en los ecosistemas.

La existencia de una pared medianera construida en (y sin ser pintada desde) la década de los 60, justo enfrente del estanque, y la transformación continua de la localidad, ha convertido esta zona en un lugar de paso obligado para viandantes y escolares. El mural fue concebido por uno de 
los autores de este texto, Diego Ortega-Alonso, y para su ejecución contó con la colaboración de Ramón Pérez Sendra.

\section{Somos creación}

La cerámica es una de las señas de identidad de Bailén. Desde tiempos inmemoriales este municipio ha sido un pueblo alfarero. Desgraciadamente, en la época del plástico y las nuevas tecnologías la cerámica se ha visto relegada a un segundo término y los conocimientos heredados de generación en generación por este oficio, corren el peligro de la desaparición. En este sentido, Murales Conciencia apuesta por difundir conceptos físicos y químicos tomando como ángulo de referencia el proceso de producción cerámico. Este se encuentra repleto de gestos técnicos que transforman naturalmente el mineral de la arcilla extraído de los cerros bailenenses para crear recipientes funcionales de cerámica, tales como platos, vasos, cazuelas, orzas, cántaros, macetas, etc., que forman parte de nuestra vida cotidiana. La fabricación cerámica es capaz de unir por sí misma patrimonio y ciencia y se constituye como una de las señas de humanidad más características desde el periodo neolítico. La capacidad de generar recipientes duraderos que permitían almacenar y cocinar una serie determinada de productos revolucionaría, a partir de entonces, el modo de vivir de las comunidades humanas. La generación de excedentes y la sedentarización estuvieron íntimamente relacionados con la gestación de un nuevo producto y su proceso de manufactura. Tanto es así que prácticamente la mitología de todas las culturas recoge la creación de piezas cerámicas como sinónimo de divinidad. Numerosas leyendas centran el origen del mundo y del ser humano en el barro y también coinciden en situar a sus artífices como dioses que modelan el mundo a su imagen y semejanza. De forma paralela, el traspaso inmaterial de saberes técnicos de generación en generación ha propiciado la instauración de un sistema de transformación físico-químico fundamentado en el valor de la experiencia. Obra de Raúl Ruiz “El Niño de las Pinturas", su ejecución tuvo lugar aprovechando el contexto de la III Feria Internacional de Cerámica Artística de la Ciudad de Bailén, CERAMIBA 2018, y el V Congreso de la Asociación Española de Ciudades de la Cerámica.

\section{Simbiosis}

Más de seiscientas personas pertenecientes a centros educativos, asociaciones locales y colectivos en riesgo de exclusión social, participaron en la creación de este mural colaborativo de casi sesenta metros de largo, coordinado por el colectivo madrileño Boa Mistura. El resultado fue la confección de una frase del escultor Pablo Serrano, que habla de la necesidad de unir ciencia y arte, y no entenderlas como disciplinas separadas por barreras que en realidad, no existen, lo que supone una declaración de intenciones para el proyecto Murales Conciencia. El tema tiene que ver con utilizar la ciencia, el arte y el patrimonio urbano para despertar una conciencia cívica de respeto por lo que es de todos, en un espacio público marginal que se encontraba muy degradado y que, gracias a esta intervención, ha sido recuperado para su uso y disfrute. Así pues, este mural ha sido realizado por varios colectivos que abarcan desde niños/as y jóvenes, hasta padres y madres, personas mayores, entidades del movimiento asociativo, profesorado o personas con discapacidad [figura 1].

\section{Hawking y la universalidad del AOVE}

¿Qué tiene que ver Stephen Hawking con Bailén? Se trata de una pregunta recurrente que se suele plantear cuando se visualiza por primera vez este mural ubicado en la Plaza de Prim. Con la elección de uno de los grandes científicos de la historia de la humanidad, Adrián Pérez "Manomatic" podía cumplir con cada uno de los criterios que hacen de Murales Conciencia un proyecto singular. En primer lugar, en este mashup artístico ha inmortalizado a uno de los padres

Tabla 1.- :Relación de entidades y personas involucradas en la ejecución colectiva del mural Simbiosis.

\begin{tabular}{|l|c|}
\hline COLEGIOS/ENTIDADES & TOTAL \\
\hline CEPr 19 DE JULIO (todo el alumnado) & 70 \\
\hline CEPr GENERAL CASTAÑOS / CEIP PEDRO CORCHADO (50 alumnos/colegio) & 100 \\
\hline COLEGIO SAGRADO CORAZÓN (6॰ y ESO) & 100 \\
\hline CEIP VIRGEN DE ZOCUECA (50), IES MEDINA RIVILLA (50) & 100 \\
\hline $\begin{array}{l}\text { PerSOnaS CON disCapacidad intelectual y familias: TALLER OCUPACIONAL (20 personas), Asoc. AFAMP (30 personas), } \\
\text { CLUB DEPORTIVO ALI-UP (25 perSOnas) }\end{array}$ & 75 \\
\hline ALUMNADO, AMPA Y PROFESORADO CONSERVATORIO REINA SOFÍA DE BAILÉN & 150 \\
\hline CENTRO DE DÍA DE MAYORES DE BAILÉN & 15 \\
\hline total participantes & 610 \\
\hline
\end{tabular}


del conocimiento de las Teorías del Universo que exploran lo que somos y de dónde venimos, en el mismo año de su muerte (2018). En segunda instancia, se refuerza la necesidad de difundir que la inclusión en nuestra sociedad es posible y debe ser una realidad, si se prestan los apoyos necesarios. Por último, con el guiño al olivar en el estampado de aceitunas de la camisa de Hawking, su autor pone de relieve que el aceite de oliva, una seña de identidad gastronómica de la provincia de Jaén, es un producto universal que nos pertenece a todos. Porque, recordemos, este mural se encuentra ubicado en un espacio en el que la gastronomía (mercado de abastos) y la cuestión social e inclusiva (Centro de Servicios Sociales de Bailén) encuentran gracias a la intervención de Manomatic, la unión perfecta a través de esta visión tan innovadora de Stephen Hawking [figura 2].

\section{Topo-grafías}

La topografía ha sido siempre una disciplina científica y técnica esencial para erigir monumentos enigmáticos de la antigüedad, aunque también ha servido a los geógrafos para conocer las propiedades y naturaleza del territorio que ha sido ocupado por las comunidades humanas. De igual modo, era imprescindible en el arte de la guerra. Por estas razones, el espacio elegido para llevar a cabo la realización de un mural ligado a la importancia de la medición, fueron las paredes y el ventanal de la terraza del Museo de la Batalla de Bailén. El conocimiento del territorio supone obtener ventaja en cualquier ámbito que tenga la pretensión de realizar alguna actividad en él. Lógicamente, en los conflictos bélicos el dominio del paisaje ha jugado tradicionalmente un papel fundamental a la hora de decantar la victoria hacia uno de los bandos enfrentados. Desde el punto de vista histórico, la idiosincrasia orográfica de Bailén y el conocimiento de ésta por parte del General Reding fue determinante para vencer por primera vez en campo abierto a la grande armée de Napoleón. La posición sobreelevada de la línea de artillería española acabó rompiendo en dos la división central gala sin causar un número de bajas numerosas entre sus soldados. Al igual que lo sucedido en las Termópilas, Zama, o las Navas de Tolosa, las tropas españolas, menores en formación y número, consiguieron desorganizar al ejército más poderoso del mundo de ese momento. El mural realizado por Ramón Pérez Sendra es una reinterpretación personal del mapa topográfico de la época. En el centro aparece esbozado el Bailén de 1808 sobre una gama cromática de curvas de nivel. A la izquierda se representa al general Reding, principal estratega sobre el campo del bando español y buen conocedor del medio geográfico. A la derecha se muestra al general Dupont, el máximo dirigente de los regimientos franceses obligado a capitular.

\section{Reforestando}

Esta intervención artística de alrededor de $300 \mathrm{~m}^{2}$, ha transformado por completo una plaza absolutamente degradada de la localidad y la ha reconvertido en un lugar de paseo, esparcimiento y contemplación. "Reforestando" es un proyecto de Doa Ocampo, que nace con la voluntad de recuperar espacios a través de temáticas vegetales relacionadas con el entorno donde se ubican. En Bailén son cinco las especies escogidas: el olivo, el clavel silvestre, la coscoja, la lavanda y el paloduz. Todas ellas están ligadas al municipio de diversas maneras: algunas, por ser plantas de cultivo tan importante para la economía local como el olivar; otras como el paloduz, cuya presencia en las cuencas de los ríos Rumblar y Guadiel ha implicado su consumo por parte de varias generaciones y alude a la memoria colectiva local; el resto, por tratarse de especies ligadas al ecosistema mediterráneo y a la flora de Sierra Morena. Las especies de flora autóctona representadas en este mural están estéticamente vinculadas a la ilustración botánica, utilizando colores planos de gamas frías y líneas que perfilan las sinuosas formas de la vegetación elegida por su autora.

\section{Bosque de neuronas}

Ramón Pérez Sendra aborda la intervención de un espacio de rampas sumamente degradado que conduce desde el Paseo de las Palmeras (uno de los puntos neurálgicos de la localidad) hasta un área vinculada a un parque infantil, muy próxima a las intervenciones de Doa Ocampo y la obra colectiva coordinada por Boa Mistura. La perspectiva de las rampas, con el Paseo de las Palmeras y el Monumento a la Batalla de Bailén de fondo, permite al autor la creación de una anamorfosis en la que los motivos pictóricos y el paisaje coinciden desde un determinado punto de vista, y unen su temática con el lugar, a través de una intrincada maraña de células nerviosas y colores, de la mezcla del paisaje y la composición del mural, donde las raíces de las palmeras son dendritas, y viceversa, en el 85 aniversario del fallecimiento de Santiago Ramón y Cajal [figura 3].

\section{Cántaros comunicantes}

Desde la época romana, los recipientes cerámicos se utilizaban para lograr el equilibrio de los líquidos contenidos en vasos comunicantes. La presión atmosférica y la gravedad son constantes en cada recipiente, por lo que la presión hidrostática es siempre la misma, sin influir su geometría ni el tipo de líquido. Esta es la base a través de la cual el muralista jiennense José Fernández Ríos construye un trampantojo que enlaza directamente con el contexto histórico y el patrimonio inmaterial de la localidad, a través de la figura de una mujer y su cántaro, que evoca al papel crucial que tuvieron las aguadoras en el desarrollo de la Batalla de Bailén y que Benito Pérez Galdós reflejase en una de sus obras dedicada a este suceso:

“Es verdad que de Bailén salían en bandadas multitud de mujeres con cántaros de agua para refrescarnos; pero de este socorro apenas podía participar una pequeña parte 
de la tropa, porque los que estaban en el frente no tenían tiempo para ello. Más de una vez aquellas valerosas mujeres se expusieron al fuego, penetrando en los sitios de mayor peligro, y llevando sus alcarrazas a los artilleros del centro. En los puntos de mayor peligro, y donde era preciso estar con el arma en el puño constantemente, nos disputábamos un chorro de agua con atropellada brutalidad: rompíanse los cántaros al choque de veinte manos que los querían coger, caía el agua al suelo, y la tierra, más sedienta aún que los hombres, se la chupaba en un segundo." (Pérez Galdós, Benito: «Bailén». Episodios Nacionales, 1.a Serie, IV episodio)

\section{Consideraciones finales}

Murales Conciencia es un proyecto singular que se alinea con la nueva definición de museo propuesta por el sector más progresista del ICOM. De acuerdo con esta, no importaría tanto el continente como el contenido y la relación que este último tenga con las personas que entran en contacto con él. Más allá de la percepción propia que se tenga de las obras que conforman el proyecto, y atendiendo principalmente a diversos condicionantes contextuales y sensoriales, los murales se encargan de narrar discursos científicos que parten de valores patrimoniales intrínsecos a la sociedad bailenense. Se trata esta de una singularidad que ha propiciado el nacimiento de un sentimiento de apropiación y arraigo en un entorno plenamente rural.

Existen datos que permiten comenzar a apreciar el potencial turístico que la configuración de una ruta física y virtual de arte público puede llegar a generar. La repercusión en el flujo turístico, y la percepción y valoración pública del proyecto, desde un punto de vista cualitativo y cuantitativo, ha propiciado unos resultados reflejados en los mecanismos de evaluación de impacto del proyecto y en el interés que este ha suscitado tanto en la población como en los diferentes eventos en los que ha sido presentado.

Tabla 1.- Herramientas, acciones, indicadores y resultados de los mecanismos de evaluación de impacto del proyecto Murales Conciencia.

\begin{tabular}{|c|c|}
\hline HERRAMIENTA/ACCIÓN & INDICADOR \\
\hline Murales colaborativos & $\begin{array}{l}\text { Simbiosis de Boa Mistura. } 610 \text { participantes de diferentes perfiles sociales (Datos desglosados en Tabla 1). } \\
\text { Mural colaborativo (exhibición) en Encuentro Guadalinfo de Punta Umbría, Huelva (más de } 800 \text { dinamizadores de } \\
\text { Centros Guadalinfo pudieron verlo, más de } 8000 \text { visualizaciones en Facebook). } \\
\text { Debido a que todos los murales se han realizado en el entorno urbano, es prácticamente imposible contabilizar el } \\
\text { número de personas que han podido asistir directamente a sus procesos de creación o visitarlos in situ. Nos remitimos } \\
\text { al censo de la localidad de } 2018 \text { (17820 habitantes) para dar una cifra referencial. } \\
\text { Número de visitantes que ha recibido el Museo de la Batalla de Bailén en } 2019 \text { (enero-octubre): 12000, nacionales } \\
\text { e internacionales. Aunque no podamos asegurar que hayan realizado la ruta diseñada al completo, sí podemos } \\
\text { certificar que han podido observar el mural Topo-grafías. }\end{array}$ \\
\hline $\begin{array}{l}\text { Participación en congresos, } \\
\text { jornadas, conferencias... }\end{array}$ & $\begin{array}{l}\text { V Congreso de la Asociación Española de Ciudades de la Cerámica. Bailén, Jaén (Junio 2018). Creación de mural } \\
\text { adscrito al programa del congreso. } \\
30^{\circ} \text { Encuentro de APECV (Asociación de Profesores de Expresión y Comunicación Visual) y } 3^{\circ} \text { Congreso de la RIAEA } \\
\text { (Red Iberoamericana de Educación Artística). Coimbra, Portugal (Junio-julio 2018). Participación con comunicación } \\
\text { oral. } 200 \text { asistentes aprox. } \\
\text { Jornadas Murales Conciencia. } 5 \text { conferencias y } 1 \text { mesa redonda. Museo de la Batalla de Bailén. (Enero 2019). No de } \\
\text { asistentes/conferencias: } 60 \text { personas (en su mayoría, alumnos del Máster de Investigación y Educación Estética y del } \\
\text { Máster de Patrimonio de la Universidad de Jaén, y también personas interesadas de la localidad y de alrededores). } \\
\text { Participación en debate abierto del grupo de arte urbano del GElIC: Museos de arte urbano: competencias y } \\
\text { posibilidades. 20a Jornada de Conservación de Arte Contemporáneo del Museo Nacional Centro de Arte Reina Sofía: } \\
40 \text { personas aprox. (Marzo 2019). } \\
\text { Congreso de Comunicación Social de la Ciencia. Universidad de Burgos, Asociación Española de Comunicación } \\
\text { Científica (Octubre 2019). Comunicación Flash oral. }\end{array}$ \\
\hline $\begin{array}{l}\text { e-mailing especializados a } \\
\text { los prescriptores y actores } \\
\text { seleccionados }\end{array}$ & $\begin{array}{l}\text { No de destinatarios de la lista de distribución de contactos del ayuntamiento: } 33 \text { medios de comunicación. } \\
\text { Lista de comunicación de la Red Guadalinfo. }\end{array}$ \\
\hline $\begin{array}{l}\text { Video-clips en canales de } \\
\text { divulgación virtuales }\end{array}$ & $\begin{array}{l}9 \text { videoclips (uno por cada mural ejecutado). } \\
\text { Visualizaciones totales Youtube: } 2329 . \\
\text { Videoclips en Instagram: } 9 . \\
\text { Visualizaciones totales: } 603 . \\
\text { (Se reflejan los datos de las publicaciones propias del proyecto, si bien los datos de visualizaciones son muy superiores } \\
\text { en los perfiles sociales profesionales de los artistas participantes). }\end{array}$ \\
\hline
\end{tabular}


Ferias y muestras del sector turístico para promoción y difusión del proyecto (a través de difusión en vídeos, cartelería y folletos)

El proyecto Murales Conciencia se integra dentro del paquete turístico de la localidad que se promociona en estos eventos

Integración de recorrido virtual en Google My Maps
Feria de los Pueblos de Jaén (Marzo de 2018 y 2019) En torno a 15000 visitantes cada edición.

Tierra Adentro. Jaén (Noviembre de 2018). En torno a 20000 visitantes.

FITUR 2018 En torno a 70000 visitantes.

FITUR 2019 En torno a 60000 visitantes.

( $N^{\circ}$ de encuentros mantenidos y contactos generados: 12. Contactos con empresas turísticas provinciales. 20 Contactos con empresas turísticas autonómicas. 100 Contactos con empresas turísticas nacionales e internacionales).

https://www.google.com/maps/d/u/1/edit?hl=es\&mid=1vPTZvlf3SNf3sH9UaamNORg0WCJ80YGU\&ll=38.09404309 537841\%2C-3.779163516671815\&z=17 [última consulta:2-11-2019]

\begin{tabular}{|c|c|}
\hline Portales web & $\begin{array}{l}\text { No de visitas a portal Ayuntamiento en el primer trimestre de 2018: } \\
\text { Enero (Visitas } 14.525 \text { | Número de páginas visualizadas 42.908). } \\
\text { Febrero (Visitas } 14.510 \text { | Número de páginas visualizadas 45.266). } \\
\text { Marzo (Visitas } 16.501 \text { | Número de páginas visualizadas 49.233). } \\
\text { En cuanto a la web del Museo de la Batalla de Bailén, donde también se encuentra ubicado el link a la exposición } \\
\text { virtual, los datos estadísticos del primer trimestre de } 2019 \text { han sido los siguientes: } \\
\text { Enero - (Visitantes - } 2157 \text { | Páginas visitadas : 4000) } \\
\text { Febrero - (Visitantes - } 1787 \text { | Páginas visitadas : 3533) } \\
\text { Marzo - (Visitantes - } 1634 \text { | Páginas visitadas : 4512) }\end{array}$ \\
\hline $\begin{array}{l}\text { Notas de prensa/apariciones } \\
\text { en medios }\end{array}$ & $\begin{array}{l}\text { No de notas de prensa/comunicaciones: } \\
\text { Artículos en Diario Ideal: } 2 \text { (uno de ellos, portada del diario en su edición impresa). Volumen de público de los medios } \\
\text { que publican: Diario Ideal. } \\
\text { Artículo en Diario Jaén: } 1 \text { ( } 66000 \text { lectores según Estudio General de Medios 2013). https://www.diariojaen.es/ } \\
\text { provincia/bailen/murales-conciencia-impulsa-el-arte-urbano-IA5453749 [última consulta:2-11-2019] } \\
\text { Los datos facilitados por el medio Bailén Diario, son de } 39836 \text { sesiones en su página en } 2018 . \\
\text { Los datos de alcance de la Red Guadalinfo, que se ha realizado numerosas acciones de promoción y difusión del } \\
\text { proyecto (como ya se ha indicado anteriormente) pueden consultarse aquí http://consorciofernandodelosrios.es/ } \\
\text { descargas/Informe_POA_2018.pdf [última consulta:2-11-2019] } \\
\text { Artículos en blog de Guadalinfo: } 2 \\
\text { Nota de prensa de FECYT } \\
1 \text { entrevista en Radio Municipal de Bailén. } \\
1 \text { aparición en las noticias autonómicas de Canal Sur Televisión (septiembre 2019). } \\
1 \text { reportaje en el programa Andalucía Directo, de Canal Sur Televisión (Octubre 2019). }\end{array}$ \\
\hline Perfiles sociales & $\begin{array}{l}\text { Cuenta en Instagram } \\
\text { Página Facebook. }\end{array}$ \\
\hline $\begin{array}{l}\text { Acciones de Divulgación de } \\
\text { la Fundación Descubre* }\end{array}$ & $\begin{array}{l}\text { Datos recabados por la fundación sobre el nº de visitas al portal EXPLORIA CIENCIA en 2018: } 487 . \\
\text { *(Datos facilitados por la Fundación Descubre }\end{array}$ \\
\hline $\begin{array}{l}\text { Publicaciones en revistas } \\
\text { especializadas }\end{array}$ & Artículo “Murales Conciencia”. Locvber, Revista Científica de Patrimonio (2018), Vol 2: 187-194.ISSN: 2603-5847. \\
\hline
\end{tabular}


No obstante, la adscripción de pertenencia por parte de la mayoría de un colectivo social, permite divulgar ciencia y que se entienda el patrimonio material e inmaterial como algo de dominio público, que merece ser conocido, conservado y promovido por el conjunto de la sociedad. La creación de esta colección museográfica en la calle ha favorecido el surgimiento de una conciencia colectiva que reivindica la necesidad de mantener, proteger y preservar el espacio público, promoviendo la gestación de una nueva realidad urbana democratizadora y responsable con su medio. El desarraigo individualista impuesto por la modernidad (Hernando 2012) ha empezado a romperse gracias a la creación de obras que hablan de lo que une a la comunidad.

La ejecución de algunos de los murales se realizó coincidiendo con importantes eventos celebrados en la localidad, como la Recreación de la Batalla de Bailén 2017, con alrededor de 4500 visitantes, o la Feria Internacional de Cerámica Artística CERAMIBA 2018 y el V Congreso Nacional de Ciudades de la Cerámica (3600 visitantes entre ambos eventos). Sólo en estas dos actividades, el municipio bailenense recibió más de 8000 visitantes de fuera de la localidad que pudieron ver los procesos de creación de los murales y, por tanto, la transformación de la ciudad.

¿Podría ser Murales Conciencia un referente o método marco para actuar en otros municipios? No necesariamente, pero sí puede servir como ejemplo para un mundo rural cada vez más desarraigado, que intenta hacer frente a crisis de identidad que condicionan su propia existencia. Un punto de partida podría ser empezar a plantear enfoques innovadores que garanticen una adaptación sostenible y sensible a los cambios asociados a la crisis económica de la última década, que han supuesto una fuerte contracción de la población rural (Pinilla y Sáez 2017). Si estas líneas sirven, al menos como reflexión, habremos cumplido con creces los objetivos planteados cuando este proyecto, ahora materializado, empezó a forjarse como idea. En nuestro caso la clave reside en recordar y potenciar de dónde venimos para proyectar un presente prometedor que vaticine un futuro sostenible. Los museos tienen una misión crucial en esta tarea y Murales Conciencia empieza a cumplirla.

\section{Notas}

[1] Tal y como Rosa Gasol, Restauradora de la Diputació de Barcelona, expuso de forma clara durante la reunión paralela a la $20^{a}$ jornada de Conservación de Arte Contemporáneo celebrada en el Reina Sofía en febrero de 2019.

[2] DONAIRE, G (2012). Los ladrillos se amontonan en Bailén. El País. Fecha de última consulta: 23/08/2019 https://elpais.com/ ccaa/2012/06/16/andalucia/1339865809 126996.html [última consulta:2-11-2019]
[3] FUNDACIÓN DESCUBRE (2019). Murales Conciencia. Exploria Ciencia. Fecha de última consulta: 23/08/2019 https:// fundaciondescubre.es/recursos/murales-conciencia/ [última consulta:2-11-2019]

[4] ORTEGA-ALONSO, D (2019). Lista de reproducción de vídeos del proyecto Murales Conciencia. Canal Youtube del Centro Guadalinfo de Bailén. Fecha de última consulta: 28/08/2019 https://www.youtube.com/playlist?list=PLX3qa9QSsW56aWlcQWjPrZSM62b-pG6- [última consulta:2-11-2019]

\section{Bibliografía}

BAUMAN, Z. (2010) Mundo-consumo: ética del individuo en la aldea global. Editorial Paidós Mexicana.

CÁRDENAS, A., AGUDO, J. A. (2012). La Edad del Barro. Granada: Port-Royal.

CHRISTENSEN, C. M., RAYNOR, M. E., MCDONALD R. (2015) “What is disruptive innovation." Harvard Business Review 93.12 : 44-53.

FUNDACIÓN ESPAÑOLA PARA LA CIENCIA Y LA TECNOLOGÍA (2018). "Percepción Social de la Ciencia y la Tecnología en España". Recuperado de: https://icono.fecyt.es/sites/default/ files/filepublicaciones/18/epscyt2018 informe 0.pdf [última consulta:2-11-2019]

GARCÍA, J., GARCÍA. M. R. (2016). “El turismo cultural en Málaga: Una apuesta por los museos." International journal of scientific management and tourism 2.3: 121-135.

HERNÁNDEZ, F. (1993): "Evolución del concepto de Museo." Revista General de Información y Documentación 2.1:85-97.

HERNANDO, A. (2012): La fantasía de la individualidad. Sobre la construcción sociohistórica del sujeto moderno. Buenos Aires: Katz editorial.

ICOM (2019): “Definición de Museo”. Recuperado de: https://icom. museum/es/actividades/normas-y-directrices/definicion-delmuseo/ [última consulta:2-11-2019]

LORA, P., ROCHA, D. (2016). "Promoción de la innovación social a través de la utilización de metodologías participativas en la gestión del conocimiento". Equidad y Desarrollo, (25): 159-178.

MARTOS, E., y GARCÍA, A. E. M. (2014). "Artefactos culturales y alfabetización en la era digital: discusiones conceptuales y praxis educativa". Teoría de la educación. Revista Interuniversitaria, 26 (1 (en-jun), 119-135.

ORTEGA-ALONSO, D. (2018). "Murales Conciencia". Locvber, Vol 2: 187-194

ORTEGA-ALONSO, D. (2019). “Personalidad artística en ilustración científica: Un estudio de caso." Tercio Creciente, 15, págs. 55-72. 
PÉREZ GALDÓS, B. (2014): Episodios Nacionales (todas las series, con índice activo). E-artnow.

PINILLA, V., SÁEZ, L. A. (2017). “La despoblación rural en España: génesis de un problema y políticas innovadoras". CEDDAR, Zaragoza.

REMESAR, A. (2000). “@rte contra el pueblo. Tensiones entre la democracia y el arte público." Publicacions de la Universitat de Barcelona. Monografías socioambientales 24

REMESAR, A. (2019). “Del arte público al post-muralismo. Políticas de decoro urbano en procesos de Regeneración Urbana." On the W@terfront. Public Art. Urban Design. Civic Participation. Urban Regeneration, 61(1), 3-65.

SERRANO-MARTÍNEZ, C. (2016). “El arte urbano como instrumento de empoderamiento y visibilización. El Festival de Asalto." Comunitania: revista internacional de trabajo social y ciencias sociales, 11, 9-26.

SILBERBERG, T. (1995). "Cultural Tourism and business opportunities for museums and heritage sites". Tourism Management, Vol.16, no. 5: 361-365.

TOHARIA, M. (2010). “Políticas de comunicación universitaria y divulgación científica." La Cuestión Universitaria 6: 95-102.

VISCONTI, L. M., SHERRY JR, J. F., BORGHINI, S., ANDERSON, L. (2010). "Street art, sweet art? Reclaiming the "public" in public place". Journal of consumer research, 37(3), 511-529.

\section{Referencias web}

Fundación Española para la Ciencia y la Tecnología. Informe de resultados de Percepción Social de la Ciencia y la Tecnología (2018). Referencia web: https://icono.fecyt.es/informes-ypublicaciones/percepcion-social-de-la-ciencia-y-la-tecnologiaen-espana [última consulta 24-10-2019]

Conferencia OMT/UNESCO: El turismo cultural mantiene las comunidades y el patrimonio vivo. Referencia web: http:// www2.unwto.org/es/press-release/2018-12-05/conferenciaomtunesco-el-turismo-cultural-mantiene-las-comunidades-y-elpat [última consulta 24-10-2019]

Ruta virtual de Murales Conciencia en la plataforma Explora Ciencia, de la Fundación Descubre. Referencia web: https:// idescubre.fundaciondescubre.es/exploria-ciencia/muralesconciencia/[última consulta 24-10-2019]

Ruta virtual de Murales Conciencia en página web del Ayuntamiento de Bailén. Referencia web: http://www.ayto-bailen. com/index.php/component/content/article/95-news/2781murales-conciencia [última consulta 24-10-2019]

Museo de la Batalla de Bailén. Referencia web: http:// museobatalladebailen.es [última consulta 24-10-2019]

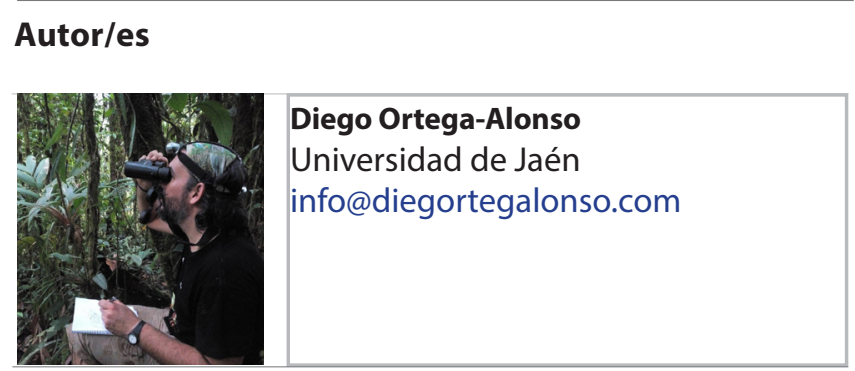

Licenciado en Bellas Artes por la Universidad de Granada. Máster en Investigación y Educación Estética y Doctorando en Patrimonio por la Universidad de Jaén. Sus líneas de trabajo se extienden en torno a temas como la investigación en artes, la divulgación de la ciencia a través del arte, la ilustración científica, la innovación social o la inclusión de las personas con discapacidad intelectual y colectivos en riesgo de exclusión social. Agente de Innovación del Ayuntamiento de Bailén en la Red Guadalinfo, es responsable e investigador principal del proyecto Murales Conciencia, financiado por FECYT.

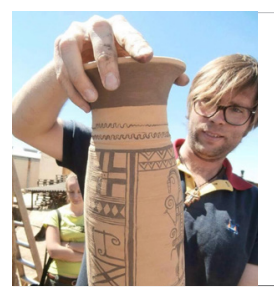

\section{Juan Jesús Padilla Fernández}

Patrimonio del Ayuntamiento de Bailén juanjpad@ucm.es / jjpadilla@ayto-bailen.com

Doctor internacional en Historia y Arqueología por la Universidad Complutense de Madrid con la calificación de Cum Laude. Actualmente gestiona y dirige el área de Patrimonio del Ayuntamiento de Bailén, así como el Museo de dicha localidad, centrado en recordar la célebre Batalla de Bailén. Desde esta posición, ha promovido múltiples actuaciones de carácter cultural que han ayudado a enriquecer y fomentar el patrimonio material e inmaterial de este municipio jiennense. Uno de ellos es precisamente Murales Conciencia, financiado por FECYT. 